\title{
The Universe Among Other Things
}

\author{
Achille C. Varzi \\ Department of Philosophy, Columbia University
}

[Final version published in Ratio 19:1 (2006), 107-120]

\begin{abstract}
Peter Simons has argued that the expression 'the universe' is not a genuine singular term: it can name neither a single, completely encompassing individual, nor a collection of individuals. (It is, rather, a semantically plural term standing equally for every existing object.) I offer reasons for resisting Simons's arguments on both scores.
\end{abstract}

\section{Introduction}

About ten years ago Bas van Fraassen published an argument to the effect that 'world' is not a count noun and, therefore, 'the world' is not a designator. ${ }^{1}$ Van Fraassen's point was that 'world' is a context-dependent term whose function is to indicate the domain of discourse of whatever sentence it occurs in, on the occasion of the utterance, and that it makes no sense to suppose that there is a single thing that encompasses all domains as parts-it makes no sense to suppose that there is such a thing as the world. Presumably, the same account would apply to such words as 'universe' and, consequently, to the semantic status of 'the universe'. In a recent article, Peter Simons has argued that the resources of analytic ontology (about which van Fraassen expressed scepticism) allow us to give a different answer. ${ }^{2}$ For Simons there is indeed no such thing as the universe, but there is none the less a precise and perfectly legitimate sense in which we may speak of 'the universe': it is a semantically plural term standing equally for every existing object (like 'the current fellows of the Royal Society' is a plural term standing equally for every person that is currently a fellow of the Royal Society).

Simons's outline and defence of his positive view are compelling, and the view may well turn out to be the best option that is available all things considered. However, this defence builds on a pars destruens that is reminiscent of van Fraassen's scepticism concerning the possibility that, to put it in the material

\footnotetext{
1 Van Fraassen (1995).

${ }^{2}$ Simons (2003).
} 
mode, the universe is one thing among others. Two main options are considered and rejected on this score: (i) that the universe is a single, completely encompassing individual, and (ii) that the universe is a (the) collection comprising all there is. Simons looks askance at both options and concludes that the expression 'the universe' does not name a single fixed entity at all, whether individual or collective. At best it could name (iii) a system given structure by laws (physical or otherwise), i.e., an empirical collection whose members happen to coincide with the plurality of all the existing objects-but even that possibility is looked at somewhat sceptically. I have no qualms with regard to (iii). But I want to argue that Simons's reasons for rejecting the first two options and concluding that the universe is not a single entity but a multiplicity are not as cogent as they look. In fact, my preference would go to option (i), but I think option (ii) is also available - or so I will argue.

\section{The Universe as an Individual}

Let us start with Simons's reasons for looking askance at the idea that 'the universe' names a fixed individual. Simons's misgivings here have a familiar tone. If the universe were an individual, then it would have to be the universal individual - the mereological sum or fusion of all there is. But unless we assumed a monocategorial ontology (so that 'all there is' means all material objects, or all events, or all tropes, or what have you-an option that Simons rejects in the third part of his article), this universal individual would have to be awfully gerrymandered, and for Simons gerrymandered sums are weird. At least, such a gerrymandered sum would be weird, and not just in the usual sense in which the sum of Chisholm's left foot and Grand Central Station-if such there be-is weird. ${ }^{3}$ The universal sum would be weird because it would have parts in different ontological categories. And if it had parts in different categories, then we would seem to have no principled reason to accept any of the following logically exhaustive options concerning the category of the universe itself: ${ }^{4}$

(a) The universe is in one of the categories occupied by its proper parts. (But-Simons says - why should a single category 'trump' all the others and get this exclusive privilege?)

\footnotetext{
3 The charge can be traced back to Lowe (1953) and Rescher (1955); for more recent formulations see e.g. Wiggins (1980), Chisholm (1987), van Inwagen (1990), and Sanford (2003). For a defense of the unrestricted principle of mereological fusion see Goodman (1956) and, more recently, Lewis (1991), Jubien (1993), and Rea (1998) inter alia.

${ }^{4}$ See Simons (2003), p. 238.
} 
(b) The universe is in a different, sui generis category unshared by any of its proper parts. (But, again, why should the universe enjoy such an exclusive privilege?)

(c) The universe is in more than one category, possibly in all categories occupied by its proper parts. (But wouldn't this be an ad hoc exception to the idea that categories are mutually exclusive?)

(d) The universe is in no category at all. (And wouldn't this be an ad hoc exception, too?)

Now, I agree that if the universe were the only entity with parts in different categories, each of these options would be embarrassing and ultimately unacceptable. However, the universe cannot be the only such entity. If the universe has parts in different categories, then so does the universe minus Chisholm's left foot, or the universe minus Sebastian's stroll in Bologna, or the universe minus the number 42. If the universe has parts in different categories, then so do lots of its proper parts: there is no obvious reason to rule out those mereological sums if we are considering countenancing the universal sum..$^{5}$ But then the situation is not as bad as Simons portrays it. Options (b) would still cry for a justification and options (c) and (d) would remain utterly ad hoc, and for this reason alone unacceptable. Option (a), however, would be perfectly reasonable. Whatever category hosts that thing that is the universe minus Chisholm's left foot can host the universe as a whole, and that category gets the privilege precisely because its members have parts in all categories. There would be a problem if the universe minus Chisholm's left foot, the universe minus Sebastian's stroll in Bologna, the universe minus the number 42 , and so on, were themselves in different categories. (In that case we would be forced to put the universe in more than one category, as per (c).) But there is no reason why that should be the case. Those parts of the universe are equally representative of all there is and will therefore be in the same category. And the whole universe can be in that category, too.

Of course one may still wonder what category will bag those things. In other words, one may raise in their regard the same sceptical objections that Simons raises in relation to the whole universe: What are the options when it comes to categorizing such gerrymandered, transcategorial beasts?

It seems to me that there are two viable options. The first is simply to say that such things are mere mereological sums. On the face of it, some philoso-

5 This is a bit quick. For example, Sharvy's (1983) "quasi-mereologies" have a universal individual but no unrestricted fusion. However, such theories are still closed under least upper bounds (with respect to parthood), and for the present purposes that is enough. (On the difference between fusion and least upper bound, see Simons 1987, pp. 32ff.) 
phers think that 'mereological sum' itself names an ontological category, to be included in a comprehensive inventory alongside various other putative categories such as object, event, trope, and so on; for they think that mereological sums have identity conditions of their own. ${ }^{6}$ For example, it is sometimes argued that the mereological sum of an object's parts has different identity conditions when compared to the object itself: the sum, but not the object, may survive any rearrangement of the parts; the object, but not the sum, may survive the annihilation of some parts; and so on. Thus, if mereological sums form a category of their own, then that category would fit the bill. It would host the universe just as it would host its gerrymandered parts, unless of course one worries about the legitimacy of such parts in the first place.

I personally do not find this option attractive, for I do not share the view that a thing is different from the mereological sum of its parts, ${ }^{7}$ hence I see no reason to think that mereological sums form a category of their own. But then another option suggests itself naturally. If a thing is just the sum of its parts, and if the parts belong to different categories, when none of these categories is powerful enough to trump the others the thing will have to belong to a different category. Now, if the universe were the only case where this happens, positing a new category would be unacceptably sui generis. But the universe would not be the only case where this happens. We have just seen that the universe would belong to the category of some of its parts, namely the category of such parts as that thing that is the universe minus Chisholm's left foot. It is such more basic hybrids as, say, the sum of Chisholm's left foot and Sebastian's stroll in Bologna that might call for a special category. That thing is not an object, as Chisholm's left foot is; and it is not an event, which is what Sebastian's stroll is. The foot+stroll is a different sort of thing. But this would not mean that we need a sui generis category for this purpose, a category unshared by anything else. Lots of other things will be in the same category as the sum of Chisholm's left foot and Sebastian's stroll in Bologna-for example, the sum of Chisholm's right foot and Sebastian's stroll in Bologna, or the sum of Chisholm's right foot and Sebastian's stroll in Prague. Generally speaking, there is nothing wrong or peculiar in the thought that a transcategorial sum belongs to a different category than any of its single-category parts, for this would not be an exclusive privilege but a common feature of a large variety of hybrid things. (1987).

6 See Wiggins (1980) and Lowe (1989) inter alia. The view is defended also by Simons

${ }^{7}$ More generally, I accept the principle of mereological extensionality, whose main motivation goes back once again to Goodman (1956). See Casati and Varzi (1999), cap. 3. 
In the end, then, the objection to treating the universe as an all-encompassing individual must boil down to a general objection against hybrid, transcategorial entities - not because there is no coherent way to classify them, but because the necessary categories to classify them might not be as "natural" as others. Actually, there is no compulsion to suppose that we always need a new category to accommodate transcategorial sums. Perhaps in some cases there is already a good category available to do the job. (For instance, perhaps the mereological sum of an object and a property may be classified as a fact, and this category might already be needed to classify other ontological beasts - sums of events and properties, say, or atomic facts.) But it seems clear that in a polycategorial ontology at least some trascategorial sums call for unheard-of categories. And in the end this is the issue: What do we do in such cases? Shall we declare non-existent all those sums for which our palette of ontological categories is too poor? Shall we only accept intracategorial sums? No matter how we answer them, these are not questions about the universe but general questions about mereology and the theory of categories broadly understood.

I for one am inclined to be quite liberal in this regard. For one thing, not only do I think that a thing is identical with the mereological sum of its constituent parts. I also share the view that a thing is 'nothing over and above' its parts, ${ }^{8}$ hence I don't think the question of the existence of a mereological sum makes much sense in case we already agree on the existence of the pieces. The sum is just the pieces 'counted loosely', as some like to say. ${ }^{9}$ I hold this to be true of "natural", categorially homogeneous sums, such as the sum of Chisholm's left foot and the rest of his body, as well as hybrid, trascategorial sums, such as the sum of Chisholm's left foot and Sebastian's stroll. We may feel uneasy about treating the latter as bona fide entities (which is why we have a hard time coming up with good names and category labels), but this psychological fact has no bearing on the question of their ontological status. Actually, in some cases we may even feel at home with a transcategorial sum. Take a tornado-say hurricane Gloria. An object? Not really: the water molecules, the leaves, and the other stuff that is involved in the hurricane might all be objects, but the hurricane is something over and above all that. An event, then? No-because hurricanes move, or so we find it natural to say, while events are temporally extended and thus it makes no sense to say that they move. There are lots of little events

8 Lewis 1991, 81. The phrase (and the 'ontological innocence' of mereology that it is meant to capture) has been questioned by various people, most notably van Inwagen 1994, Yi 1999, and Merricks 1999. My own reasons in support of the view are detailed in Varzi 2000.

${ }^{9}$ Baxter 1988, p. 580. 
involved in Gloria, but the hurricane itself is something over and above such events. So maybe we can say that Gloria includes both objects and events as parts - it is a transcategorial sum. Yet it is a perfectly "natural" entity. (There maybe some indeterminacy as to whether we should say that a water molecule is a part of or a participant in Gloria, but this very fact shows that both options are prima facie plausible.)

Moreover, even within the range of categorially homogeneous sums there are lots of weird, gerrymandered candidates. Just to run through some familiar examples, consider a sum of spatially disconnected things, such as Chisholm's left foot and Quine's right foot. Or consider a sum of things that do not co-exist, such as Chisholm's left foot and Descartes's right foot. Or, again, consider a sum of things that are connected and co-exist, but are nevertheless heterogeneous in some sense, such as a glass and the wine inside it, or a doughnut and the volume of air that fills the hole. To some philosophers, sums such as these are just as problematic as genuinely transcategorial sums. But then we know it's hard to draw a line. In our universe everything is odd and gerrymandered to a degree. Even a smooth surface may, on closer look, be like the top of a fakir's bed of nails (to borrow a nice phrase of Simons's ${ }^{10}$ ). All things are on closer look like the figures of a Seurat painting, so what shall we do-get rid of them all? I'd rather keep them all. The question of what figures are salient and what aren't - what sums are natural and what aren't-is an interesting one, but it has no ontological significance. Who are we to decide what there is and what there isn't on the basis of our standards for salience and ontological beauty, let alone our modest apparatus of categorial distinctions?

(There are many interesting cases in sciences, too, where the lack of categories proved problematic. When Marco Polo saw the rhinoceroses in Java, the best he could do was to classify them as unicorns. When the Aztecs hastened to the coast to witness the landing of the first conquistadores, they thought the Spaniards were riding deer because they could not think of a different sort of quadruped of that size. Not to mention the Australian colonists who first ran into that weird 'duck-billed' animal we now call the platypus. What sort of beast was that? Not a mole, because of the beak. Not a duck, because of the four legs. Not a mammal, because it laid eggs. Not a reptile, because it had warm blood. Still in 1800 the German anatomist Johann Blumenbach came up with the name Ornithorynchus paradoxus. Not a good name, perhaps, but a telling one: one way or the other the beast was there and a new category was wanted. ${ }^{11}$ )

10 Simons (1991), p. 91. Maybe all boundaries are like that? See Smith and Varzi (2000).

${ }^{11}$ I am taking these examples from Ritvo (1997) and Eco (2000). 


\section{The Universe as a Set}

So my moral is that Simons's reasons for ruling out the first hypothesis, to the effect that 'the universe' names a single, completely encompassing individual, are not conclusive. Let me now move to the second main option considered and rejected by Simons, namely that the expression 'the universe' names a fixed collection of individuals - a set (or class). Simons says this can't be right, and for two independent reasons. ${ }^{12}$ First, if it were a set it would belong to a specific ontological category, while its members may be of different categories. It would be an abstract entity and would not, therefore, partake of the nature of its nonabstract elements; it would only touch them at arm's length. Second, if the universe were a set it would have to be the universal set, a set containing everything including itself, and under standard set-theoretic assumptions there is no such set.

The first concern is the analogue of the one discussed above with reference to (a): the universe qua transcategorial set cannot belong to one and only one of the categories occupied by its members, for why should a single category get this exclusive privilege? Why should the category of sets trump all the others and get the exclusive? I agree that this can be an embarrassing question. And it is precisely because sets are abstract that I am not inclined to think of the universe as a set but as an individual of some sort - the merelogical sum of all there is. But once again I don't think the issue is a serious one for those who do like the prospects of the universe as a set. For them, the category of sets gets to host the universe because that is what the universe is. Take the set whose members comprise all the fellows of the Royal Society plus all of their singletons. Is there a problem in the fact that this set is in the same ontological category as some of its members but not others - that it embodies the nature of just one of its kinds? Surely not. It is a transcategorial set, but a set none the less. Well, then, the same may be true of the universe. Sets are powerful entities - they tend to take over.

As for the second reason, it is certainly correct that under standard assumptions about the existence of sets there is no such thing as the universal set. And neither is the very idea of a universal set a popular one. This is not to say, however, that it is formally incoherent or otherwise unworkable. Examples of nonstandard set theories in which the universe is a set among others can already be found in the works of Quine and Church, ${ }^{13}$ and today the topic is gaining interest among logicians and mathematicians alike. The motivations may be varied;

\footnotetext{
12 Simons (2003), p. 238.

13 See Quine (1937) and Church (1974).
} 
but it is remarkable, for instance, that the opening page of the first book devoted entirely to this sort of set theory includes a statement bearing explicitly on our subject matter:

One would naturally want the universe to be a set, since, if one thing is certain in this life, it is that everything is identical with itself, so we cannot avoid having the universe as the extension of the predicate of self-identity. ${ }^{14}$

One problem with such theories, of course, is that we are inclined to infer the non-existence of the universal set from Russell's paradox. But that's a mistake. Russell's paradox depends on the existence of the set of all sets which are not members of themselves, $\{x: x \notin x\}$, and this is not something that follows directly from the existence of a universal set. It would follow if we assumed an unrestricted separation axiom, whereby every subclass of a set is a set. But one can go a long way in set theory without the full strength of such an axiom. For another illustration, some might be inclined to reject the universal set because of Cantor's paradox. If the universal set $U$ existed, it would have to include its own power set, $\wp U$, which is impossible. Again, however, this need not be the case. That impossibility depends on a diagonal argument where we assume a surjective function $f: U \rightarrow \mathscr{\wp} U$ to be given and we consider the set of all things that are not members of their $f$-values, i.e., $\{x \in U: x \notin f(x)\}$. Plainly, the existence of this set follows from the unrestricted separation axiom, if $U$ exists; but it does not follow from $U$ 's existence alone.

So there is no obvious reason, from a purely set-theoretic perspective, why the universe can't be a set. It might be necessary to impose further restrictions on our intuitions about abstraction, but such restrictions may well have different and independently good motivations. (For instance, one may be inclined to allow only stratified sets, following Quine's advice, and that would be enough to have $U$ without paradox.)

There is, to be sure, a third reason suggested by Simons against the thought of identifying the universe with a set. Simons hints at it with reference to a slightly different version of that thought, according to which the universe is a proper class, but the difference is not significant: the main point is that if the universe were a set (class) it would be a unique collection of elements, while it would seem that the universe has no unique decomposition. ${ }^{15}$ I think this objection bites deeper. It is precisely this sort of consideration that leads some phi-

\footnotetext{
${ }^{14}$ Forster (1992), p. 1.

15 Simons (2003), p. 238.
} 
losophers to view mereology as better suited to ontology than set theory: it does not require that we specify some level of ultimate entities - the Urelementefrom out of which everything else is constructed. ${ }^{16}$ (Indeed, mereology is consistent with the hypothesis that there is no level of ultimate entities - that everything is made out of atomless gunk.) So metaphysically, if not formally, this would provide us with good reasons to look askance at the identification of the universe with a set or class. But there is an obvious reply to this line of objection. For it only applies if it is indeed assumed that the universal set is built out of Urelemente that admit of no further decomposition, and surely this assumption is not granted. Unless we buy into a monocategorial ontology consisting exclusively of sets (hardly a plausible assumption outside the realm of pure mathematics), the Urelemente of set theory may be things of various sorts, including material objects of the garden variety. And such objects may have all the mereological structure one wishes. So at least two options present themselves:

(e) The universe, construed as the universal set, encompasses everything that exists, although some of the things it encompasses (the proper parts of its Urelemente) are not included among its elements.

(f) The universe, construed as the universal set, includes everything that exists among its members, the proper parts of its Urelemente not being things that exist in actuality.

Both of these options are perfectly consistent and some might even think that one of them is correct. For instance, option (e) is germane to a mereologised version of set theory such as David Lewis's. ${ }^{17}$ And option (f) could be defended on the assumption that the relevant proper parts of the Urelemente are (arbitrary) undetached parts, together with Peter van Inwagen's reasons for not taking such parts to be things that exist in and of themselves. ${ }^{18}$ Once again, it is not my purpose here to defend any of these options. My concern is merely with the question of their tenability. And tenable they are.

\section{Concluding Remarks}

Simons is right, of course, in emphasizing certain virtues of his account vis-à-vis the options that I have been reviewing. In particular, if 'the universe' is not a

\footnotetext{
16 See e.g. Bochman (1990) and Smith (1995) for explicit formulations of this view.

17 See Lewis (1991) (though Lewis's actual formulation of the theory has no universal set but, rather, a universal proper class).

18 See van Inwagen (1981).
} 
proper singular term but a semantically plural term standing for a plural collection-a genuine multiplicity of things of various sorts - then the recurrent problem of the categorial status of the universe dissolves altogether. As a multiplicity, the universe would straddle any ontological divide among its members, so we would not have to force it all into a single category. (And Simons goes a remarkably long way towards showing the formal consistency of this account, even on the hypothesis that the categories form a full type-theoretic hierarchy.) By means of conclusion, however, let me take one more look at the source of that recurrent problem - the categorization of the universe. Exactly what counts as an ontological category is not entirely clear, as we can categorize at different levels. So what exactly is the worry raised by the assumption that a good ontology ought to be polycategorial?

Consider the opposition between continuants and occurrents. Simons regards this opposition to reflect a bicategorial ontology (like the opposition between substances and tropes, or that between concrete and abstract entities) and argues that, if both categories have members, it would be illegitimate to classify the universe one way or the other for the sorts of reasons already discussed above. ${ }^{19}$ I take it that Simons is here thinking of the continuant/occurrent distinction as corresponding to the traditional object/event distinction, and surely many philosophers would go along with such a parallel. A rotating sphere is a continuant; the rotation of the sphere is an occurrent. None the less there is room for flexibility here. Suppose we hold-as a growing number of philosophers do - that objects are not continuants but occurrents. That is, suppose we hold that objects are four-dimensional entities that persist through time by having different temporal parts at different times, just like events. ${ }^{20}$ Would this mean that we are forced into the flatness of a monocategorial ontology? As a matter of historical fact, four-dimensionalists have indeed favoured the affirmative answer. Quine, for one, held explicitly that in his desert landscapes there is no significant distinction between a material object and an event:

Each comprises simply the content, however heterogeneous, of some portion of space-time, however disconnected or gerrymandered. What then distinguishes material substances from other physical objects is a detail: if an object is a substance, there are relatively few atoms that lie partly in it (temporally) and partly outside. $^{21}$

19 Simons (2003), p. 240.

${ }^{20}$ Recent proponents of this view include Lewis (1986), Heller, (1990), Sider (2001), and Hudson (2001).

${ }^{21}$ Quine (1960), p. 131. 
However, a four-dimensionalist need not go along with this flat picture. The doctrine of temporal parts, understood as a conception of how things persist through time, is independent of the question of whether two or more distinct occurrents can share the same region of space-time, just as the theory of continuants is independent of the question of whether two or more distinct continuants can occupy the same region of space. ${ }^{22}$ And if two or more distinct occurrents can share the same region of space-time, nothing prevents them from being occurrents of different sorts. Nothing prohibits a four-dimensionalist from distinguishing a 4D rotating sphere from its 4D rotation.

Again, I am not advocating this view here. But to the extent that it is a coherent view, it brings out a difficult question underlying the very idea of a polycategorial ontology, and the thought that the universe sits ill with it. On the view under discussion there are only occurrents, but the occurrents may be of such a variety as to do justice to the intuitive distinction between objects and events. So the underlying ontology would be, in one sense, monocategorial, but in another sense it would be just as fine-grained as a bicategorial ontology. Being a monocategorial ontology, the universe (construed now as an individual as opposed to a set) would be just one entity among others. At the same time, because of its internal differentiation, one might still worry about whether the universe is objectlike or event-like (or neither). Would this be a serious worry? I say it would not. If the differentiation is not categorial-if objects and events are just different sorts of things belonging to the same broad ontological category of occurrentsthen the worry would not be genuinely ontological. It would be an instance of a typical and yet immaterial worry that arises every time we set out to mereologise with things that are not, at some level of analysis, exactly alike. (Compare worrying about whether the mereological sum of a statue and the clay constituting it, on the assumption that they are distinct, is statue-like or clay-like.)

I do not mean to suggest that the notion of an ontological category is up for grabs. But neither do I take it to be a truism that all sortal discriminations should correspond to ontologically significant categorial distinctions. As it stands, the desideratum of a polycategorial ontology is too generic to be an hindrance for the friends of the universe. We may part company with them on the grounds of our overall metaphysical views. But we may likewise side with them, precisely on those grounds.

22 For instance, Wiggins (1968), Doepke (1982), Johnston (1992), and Lowe (1995) (along with Simons 1985) think that co-location of continuants is possible; Robinson (1982), Burke (1994), and Levey (1997) think it is not (for various reasons); others have doubts: see e.g. Olson (1996). 


\section{References}

Baxter, D., 1988, 'Identity in the Loose and Popular Sense', Mind 97: 575-582.

Bochman, A., 1990 'Mereology as a Theory of Part-Whole', Logique et Analyse 129/130: 75101.

Burke, M. B., 1994, 'Preserving the Principle of One Object to a Place: A Novel Account of the Relations Among Objects, Sorts, Sortals, and Persistence Conditions', Philosophy and Phenomenological Research 54: 691-624.

Casati, R., and Varzi, A. C., 1999, Parts and Places. The Structures of Spatial Representation, Cambridge (MA), MIT Press.

Chisholm, R. M., 1987, 'Scattered Objects', in J. J. Thomson (ed.), On Being and Saying: Essays for Richard Cartwright, Cambridge (MA): MIT Press, pp. 167-173.

Church, A., 1974, 'Set Theory with a Universal Set', in L. Henkin (ed.), Proceedings of the Tarski Symposium, Providence (RI): American Mathematical Society, pp. 297-308.

Doepke, F. C., 1982, 'Spatially Coinciding Objects', Ratio 24: 45-60.

Eco, U., 2000, Kant and the Platypus, New York: Harcourt Brace and Company.

Forster, T. E., 1992, Set Theory with a Universal Set, Oxford: Clarendon Press.

Goodman, N., 1956, 'A World of Individuals', in J. M. Bochenski, A. Church, and N. Goodman, The Problem of Universals: A Symposium, Notre Dame: University of Notre Dame Press, pp. 13-31.

Heller M., 1990, The Ontology of Physical Objects: Four-Dimensional Hunks of Matter, Cambridge: Cambridge University Press.

Hudson H., 2001, A Materialist Metaphysics of the Human Person, Ithaca: Cornell University Press.

Johnston, M., 1992, 'Constitution Is Not Identity', Mind 101: 89-105.

Jubien, M., 1993, Ontology, Modality, and the Fallacy of Reference, Cambridge: Cambridge University Press.

Levey, S., 1997, 'Coincidence and Principles of Composition', Analysis 57: 1-10.

Lewis, D. K., 1986, On the Plurality of Worlds, Oxford: Blackwell.

Lewis, D. K., 1991, Parts of Classes, Oxford: Blackwell.

Lowe, E. J., 1989, Kinds of Being. A Study of Individuation, Identity and the Logic of Sortal Terms, Oxford: Blackwell.

Lowe, E. J., 1995, 'Coinciding Objects: In Defence of the "Standard Account", Analysis 55: 171-178.

Lowe, V., 1953, 'Professor Goodman's Concept of an Individual', Philosophical Review 62: 117-126.

Merricks, T., 1999, 'Composition as Identity, Mereological Essentialism, and Counterpart Theory', Australasian Journal of Philosophy 77: 192-195.

Olson, E. T., 1996, 'Composition and Coincidence', Pacific Philosophical Quarterly 77: 374 403.

Quine, W. V. O., 1937, 'New Foundations for Mathematical Logic', American Mathematical Monthly 44: 70-80.

Quine, W. V. O., 1960, Word and Object, Cambridge (MA): MIT Press.

Rea, M., 1998, 'In Defense of Mereological Universalism', Philosophy and Phenomenological Research 58: 347-360.

Rescher, N., 1955, 'Axioms for the Part Relation', Philosophical Studies 6: 8-11.

Ritvo, H., 1997, The Platypus and the Mermaid, Cambridge (MA): Harvard University Press.

Robinson, D., 1982, 'Re-Identifying Matter', Philosophical Review 91: 317-341.

Sanford, D., 2003, 'Fusion Confusion', Analysis 63: 1-4. 
Sharvy, R., 1983, 'Mixtures', Philosophy and Phenomenological Research 44: 227-239.

Sider T., 2001, Four-Dimensionalism. An Ontology of Persistence and Time, New York: Oxford University Press.

Simons, P. M., 1985, 'Coincidence of Things of a Kind', Mind 94: 70-75.

Simons, P. M., 1987, Parts. A Study in Ontology, Oxford: Clarendon.

Simons, P. M., 1991, 'Faces, Boundaries, and Thin Layers', in A. P. Martinich and M. J. White (eds.), Certainty and Surface in Epistemology and Philosophical Method. Essays in Honor of Avrum Stroll, Lewiston (NY): Mellen Press, pp. 87-99.

Simons, P. M., 2003, 'The Universe', Ratio 16: 237-250.

Smith, B., 1995, 'Formal Ontology, Common Sense, and Cognitive Science', International Journal of Human-Computer Studies 43: 641-667.

Smith, B., and Varzi, A. C., 2000, 'Fiat and Bona Fide Boundaries', Philosophy and Phenomenological Research 60: 401-420.

van Fraassen, B. C., 1995, “'World” Is Not a Count Noun', Noûs 29: 139-157.

van Inwagen, P., 1981, 'The Doctrine of Arbitrary Undetached Parts', Pacific Philosophical Quarterly 62: 123-137.

van Inwagen P., 1990, Material Beings, Ithaca (NY): Cornell University Press.

van Inwagen, P., 1994, 'Composition as Identity', Philosophical Perspectives 8: 207-220.

Varzi, A. C., 2000, 'Mereological Commitments', Dialectica 54: 283-305.

Wiggins, D., 1968, 'On Being in the Same Place at the Same Time', Philosophical Review 77: 90-95.

Wiggins, D., 1980, Sameness and Substance, Oxford: Blackwell.

Yi, B.-U., 1999, 'Is Mereology Ontologically Innocent?', Philosophical Studies 93: 141-160. 